\title{
NEW INSTITUTIONAL ECONOMICS AND METHODS FOR MEASURING THE ADAPTATION OF BULGARIAN AGRICULTURE
}

\author{
M. Georgiev*, A. Roycheva \\ Department of Economics, Agricultural University, Plovdiv, Bulgaria
}

\begin{abstract}
The purpose of the current research is to introduce the New Institutional Economics (NIE) with the focus placed on Bulgarian agriculture. On the one hand, this includes the description of institutional impact on the separate actors, operating within agricultural organizations. On the other hand, attention should be paid to the way in which the transaction costs of different economic agents are measured. Another aspect of great significance for the study is the application of this approach. This means to adjust the specific research frameworks. The article also includes a methodical dimension. Five methods have been presented: (1) a method for evaluation of the impact of institutional change on adaptability; (2) a method for evaluation of institutional alternatives on a micro-level by measuring transaction costs; (3) a method for evaluation of the effects of change in different time periods; (4) a method for evaluation of processes through the number and type of transactions; (5) a method for analysis of the relation between property rights and transactions for assessment of asset specificity. The methods can integrate various types of evaluation of one and the same economic organization (system) in a single analytical framework.
\end{abstract}

Key words: NIE, institutional impact, transaction cost, adaptation, agriculture, methods JEL: B52; B4; Q1

\section{INTRODUCTION}

Bulgarian farmers frequently complain about having to deal with plenty of activities, which are outside of their direct competences: registration procedures, issuing of documents, wasting time waiting in queues, etc. The reason for that are the so called "bad" rules. On the other hand, the organizations which establish the rules, are often guided by shortterm goals, and the evaluation of the impact of rules is one-sided, with a very short perspective and taking into account predominantly the juridical aspects involved. This article aims at completing the analysis of rules. Of course, the desire to economize some of their effects should rather lead to "synthetic" solutions, where not everything is universal. The focus of the research is directed towards the formal aspect of rules. Rules are determined by the legislation. The rate of social return of formal rules is considered to be higher than the one of informal ones, without ignoring the fact that this is not connected with the effect generated by the rules. Both formal

\footnotetext{
*Correspondence to: Minko Georgiev, Agricultural University - Plovdiv, Bulgaria, Department of Economics, 12 Mendeleev Blvd., 4000 Plovdiv, Bulgaria, tel.: +359 32654 435, e-mail:mm72gg@gbg.bg
}

rules and informal norms can exert a positive or a negative influence on society.

Bulgarian agriculture critically needs a precise evaluation of the trends of development of the accompanying social relations over the last twenty-seven years. The current inefficient state of agriculture can be explained in many different ways, but the New Institutional Economics (NIE) can provide an answer to the question about the behavioural causes for this situation. Of course, the purely educational aspect of these methods is important as well. The adjustment of such methods can also serve for the purpose of evaluating agricultural technologies. In addition, the methods are significant for the ordinary farmers. The assessment of micro-activities may show the existing relation between market barriers, collecting information and the cases when rentseekers in agriculture are involved.

The NIE is suitable for:

$>$ Entrepreneurs who must make investment decisions, enter and exit the market: in terms of primary production factors, food safety [1], plant protection and environment, and other property rights;

$>$ The possibility at a company level to benefit from knowing at which point in 
time to buy or rent a given asset (typical for the agricultural land market);

$>$ The means to overcome administrative barriers and bureaucracy by comparing alternatives and cost effects originating from them in the cases when regulatory authorities (monitoring water, environment, food safety, etc.) assimilate property rights in their favour;

$>$ The possibilities for organizational integration through a rearrangement of the governance structure in agriculture;

$>$ The way to study rules, their change and how to direct this change.

\section{NEW INSTITUTIONAL ECONOMIC SCIENCE}

The term "new institutional economics" was coined by Oliver Williamson in 1975. This approach upgrades classical economics. It describes the rules, market mechanisms, norms, opportunity behaviour, costs in economic processes - not only production ones, but also transaction costs. The NIE aims at finding integrated solutions in economic organizations, following the influence of rules, by measuring the external effects as transaction costs. There are two main doctrines in NIE: the first one is concerned with institutions. The focus here is on institutional impact. "Institutions are the rules of the game" [2]. It is they that determine human conduct and what takes place in economic organizations. Institutions are the social, informal norms, as well as laws, regulations, and limitations, etc.

The second direction treats the economic organization as a contract. The contract can be viewed as a framework within which a coordination "governance structure" exists and develops. This governance structure defines the dynamics of organizations and the individual transactions of economic actors. This is also crucial for resource allocation performed by the systems of property rights [3]. By means of the governance structure of a contract, property rights are distributed, which directs information [4] and determines opportunity behaviour. The second doctrine performs this evaluation through transaction costs [5].

\section{INSTITUTIONAL IMPACT, INSTITUTIONAL CHANGE AND WAYS TO ANALYSE THEM FOR THE NEEDS OF BULGARIAN AGRICULTURE}

This branch of theory considers institutions and their effect on the behaviour in organizations. Institutional impact defines institutional change. According to North [2], institutional change should be based on adaptive efficiency. The approach concerns the relation between cognitive processes and individual behaviour on the one hand, as a prerequisite for the ongoing actions in contemporary organizations and their economic results, and, on the other hand, the evolutionary dependence of organizations on institutional environment. Institutions, however, constantly change. Institutional change is of enormous significance for the way in which a society develops. It can also be considered an important factor for economic improvement. Furthermore, the institutions, which are contained within process organization frameworks - contracts, are also significant. Contracts are probably the most essential institution.

Institutional change can be based on the rational contract choice [6]. Change should be connected with the creation of institutional alternatives, which should lead to a low-cost conduct of economic agents. A fundamental question remains - what the incentives should be to develop new, competitive institutions. The approach developed for the purposes of this research should find means of studying institutions and their change in order to justify practical solutions for the adaptation of the agents in Bulgarian agriculture.

\section{TRANSACTION COSTS AND HOW TO EVALUATE AGRICULTURAL ORGANIZATIONS}

In theory, transaction costs are known as "social costs" [7]. They comprise of both private costs and the total costs paid by a given community. These costs are exchange costs, including in themselves externalities. In order to understand the features of transaction costs, they should be analysed at a process level. Firstly, these are the costs of processes outside production costs. Transaction Cost Economics (TCE) analyses these costs with micro-acts (transactions). For example, such are the actions aimed at collecting information, property rights exchange and protection [8], but transaction costs are: costs influenced by individual choice and costs influencing choice [9]. It can be concluded that transaction costs measure the effect of irrational transactions (opportunity behaviour). Costs belonging to the first type can mix with ones of the second, i.e. they can be combined. Then, costs can be either defined by the market, or be without a market price, i.e. the former are objectively determined by prices, while the latter are not. This turns their defining into a problematic issue. Taking this into account, it is important to define the concept of organization before the measuring of transaction costs is initiated. More precisely, after the formulation of the 
contract frame, it should be decided how to measure and evaluate, along with the transactions having a real price, the actions representing subjective alternatives [10]. Transaction costs offer the simplest and the most elegant evaluation of adaptation. Transaction costs are:

(1) Collecting information and monitoring, while at the same time it is necessary to perform physical and/or electronic communication and negotiation actions. In agriculture, these are communications between buyers and sellers and/or lawyers, notaries, information from the bargaining process, etc.; (2) Actions and costs related to property rights protection: fees, documentation, expenditures. In agriculture - the price of notary acts, cadastral plan sketches, taxes for transfer of ownership and charges for the system of property registration; (3) Costs representing effort and waste of time: waiting in queues, etc., as these costs are measured subjectively as an alternative loss according to Benham and Benham et al.'s method [11], for example waiting in queues for services at the Registry Agency.

\section{NIE IN AGRICULTURE}

In agriculture, the NIE approach directly corresponds to the theory of "contractual choice". In the context of this theory, relatively more popular is the possibility to make a choice between alternatives: rent or purchase of agricultural land [12]. The choice is made after an evaluation of the costs. In the first case - payments, which are conducted at the time of purchase (these are costs different from asset price). In the second case - costs different from rental price.

In the current study, an integrated approach is presented through which adaptation is evaluated [13]. This approach includes an aspect of integration of two doctrines: "institutional impact" and "transaction cost approach". On the other hand, it also incorporates the public choice theory. Each theory should provide practical solutions contributing to institutional adaptation.

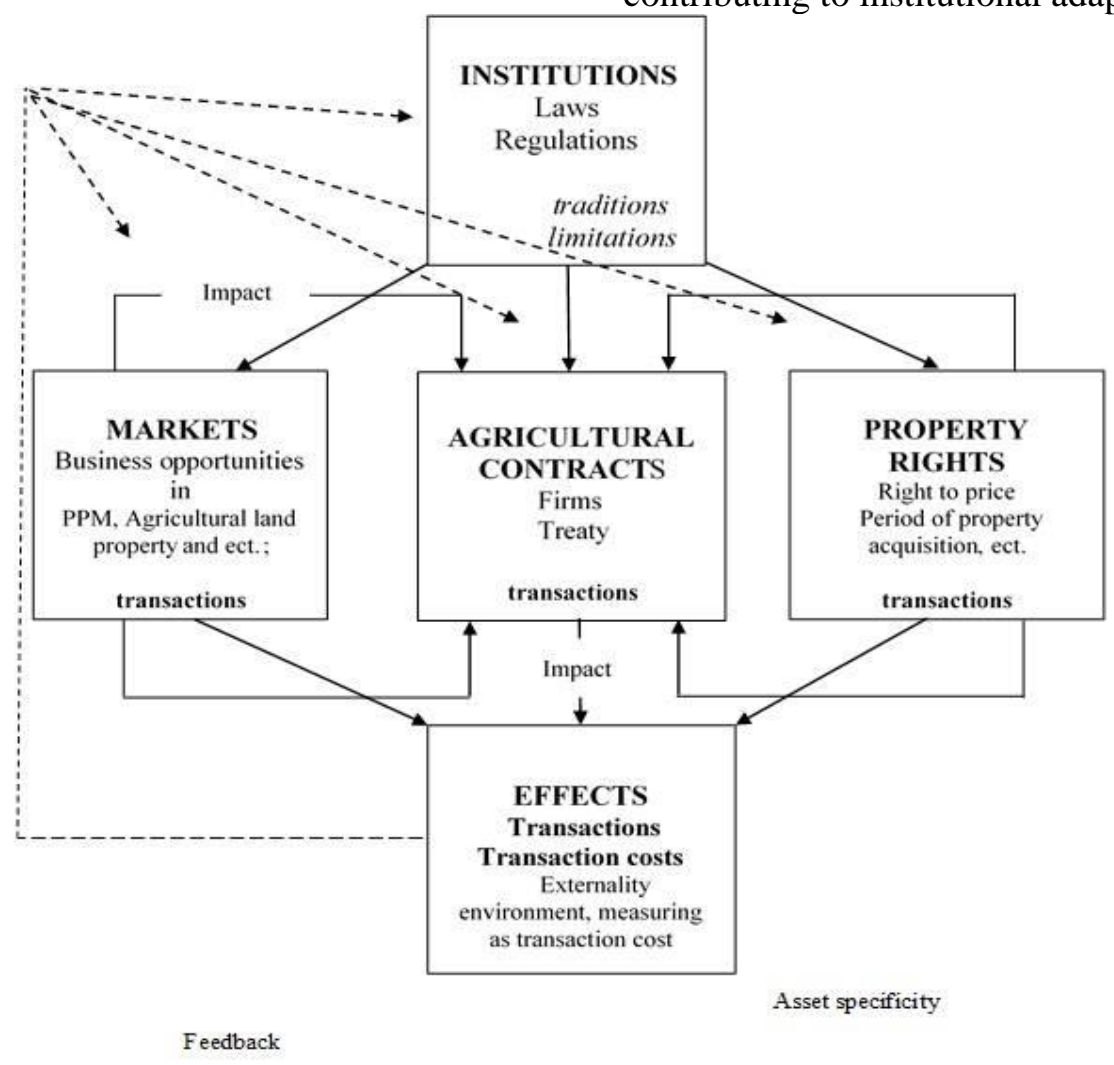

Figure 1. Analytical framework for practical research into the NIE in agriculture

For the purposes of this research, the approach integrates the relation between the choice, influenced by transaction costs, and institutions - i.e. feedback (Figure 1). In order for a more precise evaluation of the institutional matrix to exist, it is appropriate to consider the conditions, under which transaction costs exert an influence on choice, and thus modify the environment. It is possible for the NIE to focus on the institutional environment in terms of the negative external effects, generated by utilized or not utilized business opportunities. In this relation, the studies cannot be ignored, which combine the negative external effects on the environment caused by human activity, and the connection between environmental crises and transaction costs. 
EXAMPLES OF PRACTICAL

\section{APPLICATION OF NIE IN \\ AGRICULTURE}

The following figure shows an example of

institutional change.

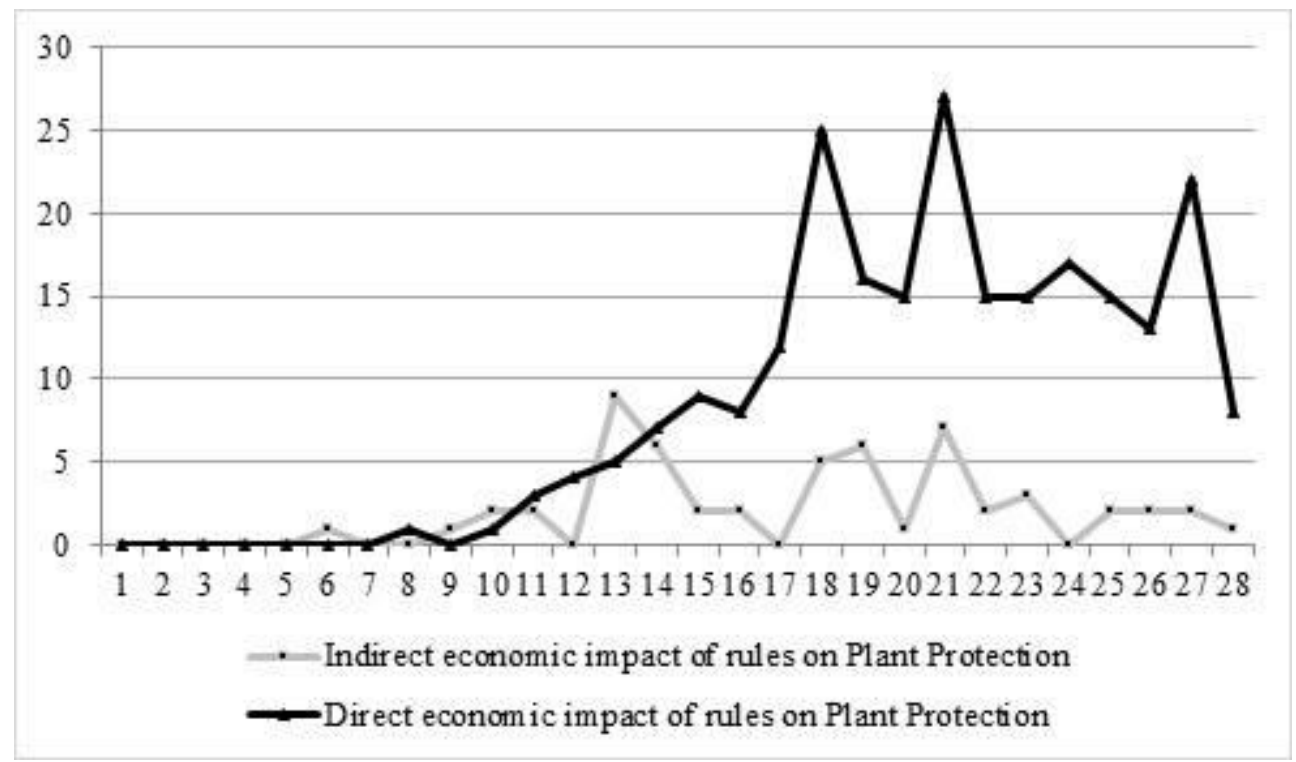

Figure 2. Quantitative dimensions of institutional change

Figure 2 shows a pattern of modification of the legislation on Plant Protection in Bulgaria. The first trend line represents the number of laws and regulations, which directly change the size of transaction costs, and the second one - indirectly, for the respective year. Change is measured quantitatively. This method is indicative for a formal institutional change leading to an accumulation of the need for re-adjustment of agents. And this, in turn, may mean that institutional change in some cases might bring about an increase of the number of alternatives, but instead of lowering uncertainty, this could expand it, and eventually, have a negative influence on transaction cost sizes. Despite the fact that this method does not present the end effect empirically, it could be presumed what the end transaction costs for the researched sector would be. The method is appropriate for an evaluation of the general influence on a macrolevel on the adaptability of the addressees of legal acts. An example follows (Table 1) of the changes in the number of transactions by years, within a concrete process - in this case: sale - purchase of agricultural land.

Table 1. Example of the measurement of number of transactions in process / year

\begin{tabular}{|c|c|c|c|c|c|c|c|c|c|c|}
\hline & average /year & 1 & 2 & 3 & 4 & 5 & 6 & 7 & 8 & Total \\
\hline 1 & Documents & 13 & 16 & 16 & 17 & 17 & 17.5 & 17 & 18 & 96.5 \\
\hline 2 & Charges and payments & & & & 11 & & & & & \\
\hline 3 & Information (bargaining + communic.) & 19 & 20 & 23 & 21 & 24 & 25 & 22.5 & 25 & \\
\hline 4 & Moving and inactivity & & & & 35 & & & & & \\
\hline 5 & "E" transactions & 2 & 2 & 1 & 2 & 2 & 3 & 1 & 3 & \\
\hline 6 & Average & & & & $\mathbf{1 7 . 2}$ & & & & & \\
\hline
\end{tabular}

Source: own research

"E" transactions should decrease the number of documents. The information transactions are not mixed with the typical "e" transactions. The same is valid also for "e" transactions for documents.

Practically, this method is a continuation of the previous one, and it demonstrates how institutional environment affects adaptability on a micro-level. The increase in the number of transactions means that the situation is getting worse. However, the increase in the number of e-transactions may sometimes lead to the contrary. This method shows adaptation in view of process integration. 
The following Table 2 provides an example of measuring transaction costs in a contract - sale - purchase of agricultural land with an evaluation amounting to $7179,49 €$. In accordance with Bulgarian legislation, the criterion, having a higher value, is used for the estimation of costs - price of agricultural land versus tax evaluation.

Table 2. Example of the measurement of transaction costs in a contract: sale-purchase/rent in Bulgaria / $€$

\begin{tabular}{|c|c|c|c|c|c|c|c|c|c|c|c|c|}
\hline & & 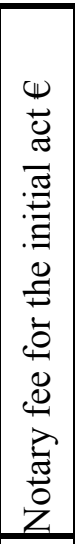 & 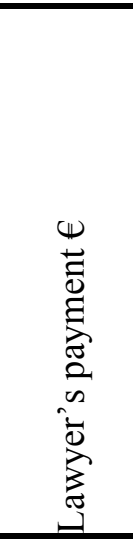 & 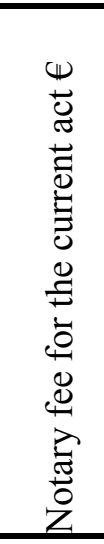 & 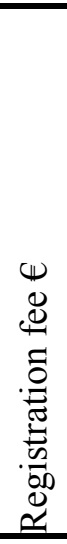 & 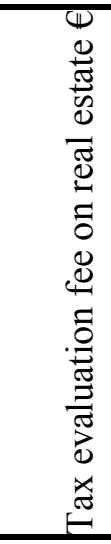 & 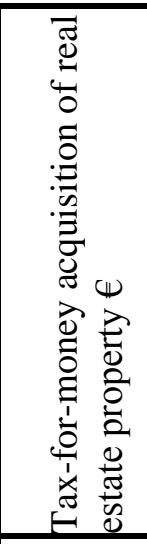 & 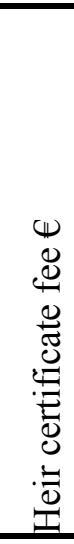 & 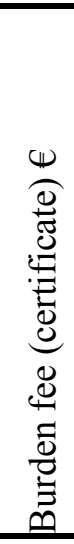 & 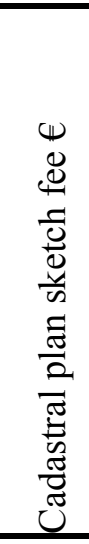 & 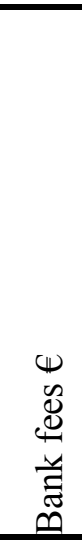 & $\frac{\pi}{\frac{\pi}{\pi}}$ \\
\hline & A & B & $\mathbf{C}$ & D & $\mathbf{E}$ & $\mathbf{F}$ & G & $\mathbf{H}$ & I & $\mathbf{J}$ & $\mathbf{K}$ & $\mathbf{L}$ \\
\hline 1 & Fees/Charges & 7 & 230,77 & 98,82 & 7 & 10 & 179,49 & 1,5 & 2 & 2 & 10 & 548,58 \\
\hline 2 & \multicolumn{12}{|l|}{ Seller /landowner } \\
\hline 3 & \multirow{3}{*}{$\begin{array}{l}\text { Moving (transport) } \\
\text { Time } \\
\text { Communication }\end{array}$} & & 10 & & & & & & & & & \\
\hline 4 & & 0 & 23 & 30 & 0 & 45 & 0 & 37 & 1 & 3 & 5 & 144 \\
\hline 5 & & & 1 & & & & & & & & & \\
\hline 6 & \multicolumn{12}{|l|}{ Buyer /tenant } \\
\hline 7 & \multirow{3}{*}{$\begin{array}{l}\text { Moving (transport) } \\
\text { Time } \\
\text { Communication }\end{array}$} & 0 & 80 & 63 & 0 & 0 & 0 & 0 & 10 & 0 & 4 & 157 \\
\hline 8 & & & 124 & & & & & & & & & \\
\hline 9 & & & 2 & & & & & & & & & \\
\hline $\begin{array}{l}\mathbf{1} \\
\mathbf{0}\end{array}$ & Total $€$ & & 230,77 & & & & & & & & & L10 \\
\hline
\end{tabular}

Source: own research

A part of the costs are objectively determined market transaction costs. These are the fees/charges, which are established in advance and they represent service price. In cell D1 of Table 2 the fee paid for the issuing of a notary act is shown. This result, however, should be measured first. The value of the deal (7 179.49 $€)$ serves as a basis to define the total sum in cell D1. The Notary Fees Tariff at the Notaries and Notary Activities Act (II, item 8, line 4) provides guidelines on the conducting of this procedure.

The total costs for fees/charges (directly determined) $-\mathrm{L} 1$, are as follows:

$\mathrm{B} 1+\mathrm{C} 1+\mathrm{D} 1 \ldots+\mathrm{n}_{\mathrm{n}}=\mathrm{L} 1$

The other part should be measured subjectively. For example, the time costs should be transformed into private missed benefit: how much the time spent waiting in queues actually costs us? How much revenue is missed due to two hours spent in a queue? The total costs for time (indirectly determined) - L1, are as follows:
$L_{\text {time }}=\mathrm{L} 4+\mathrm{L} 8$

where:

$\mathrm{L} 4=\mathrm{B} 4+\mathrm{C} 4+\mathrm{D} 4 \ldots+\mathrm{n} 4$

The total transaction costs in $€$ for the entire deal - L10 are:

$\mathrm{L} 1+\mathrm{L} 2+\mathrm{L} 3 \ldots+\mathrm{L}_{\mathrm{n}}=\mathbf{L} \mathbf{1 0}$

If we compare the total costs of two different types of deals (e.g. sale - purchase and rent), this comparison will be suitable for an evaluation of an initial investment. Depending on the costs, a decision will be made on which deal to choose. The method is also appropriate for an assessment of micro-institutional adaptability. This method may serve as a tool for the development of organizational design. For instance, to choose between a sale and rent of agricultural land, or to include or exclude a given participant in the process (if possible), and finally - to select the most appropriate institutional alternative. The following Table 3 shows the method for evaluation of asset specificity. 
Table 3. Example of asset specificity - transactions / year

\begin{tabular}{|l|l|l|l|l|l|l|l|l|l|}
\hline Transactions average /year & $\mathbf{1}$ & $\mathbf{2}$ & $\mathbf{3}$ & $\mathbf{4}$ & $\mathbf{5}$ & $\mathbf{6}$ & $\mathbf{7}$ & $\mathbf{8}$ \\
\hline 1 & Documents & +++ & + & ++ & & & + & + & ++ \\
\hline 2 & Charges and payments & +++ & ++ & & & & & & \\
3 & Information (bargaining + communic.) & +++ & ++ & & & & & & \\
4 & Moving and inactivity & +++ & +++ & +++ & & & & & \\
5 & "E" transactions & + & + & & & & & & \\
6 & Average & +++ & ++ & & & & & & \\
\hline
\end{tabular}

Legend: +++ strong; ++ middle; + weak uncertainty

Source: own research

Practically, this method verifies the strength of interaction between property rights and transactions within the investigated organizational framework. In an identical way, specificity and frequency can be determined, which would help to identify the incentives for organizations to utilize a certain coordination structure. The following figure shows the effects of the modifications in legislation, but including transaction costs as well.

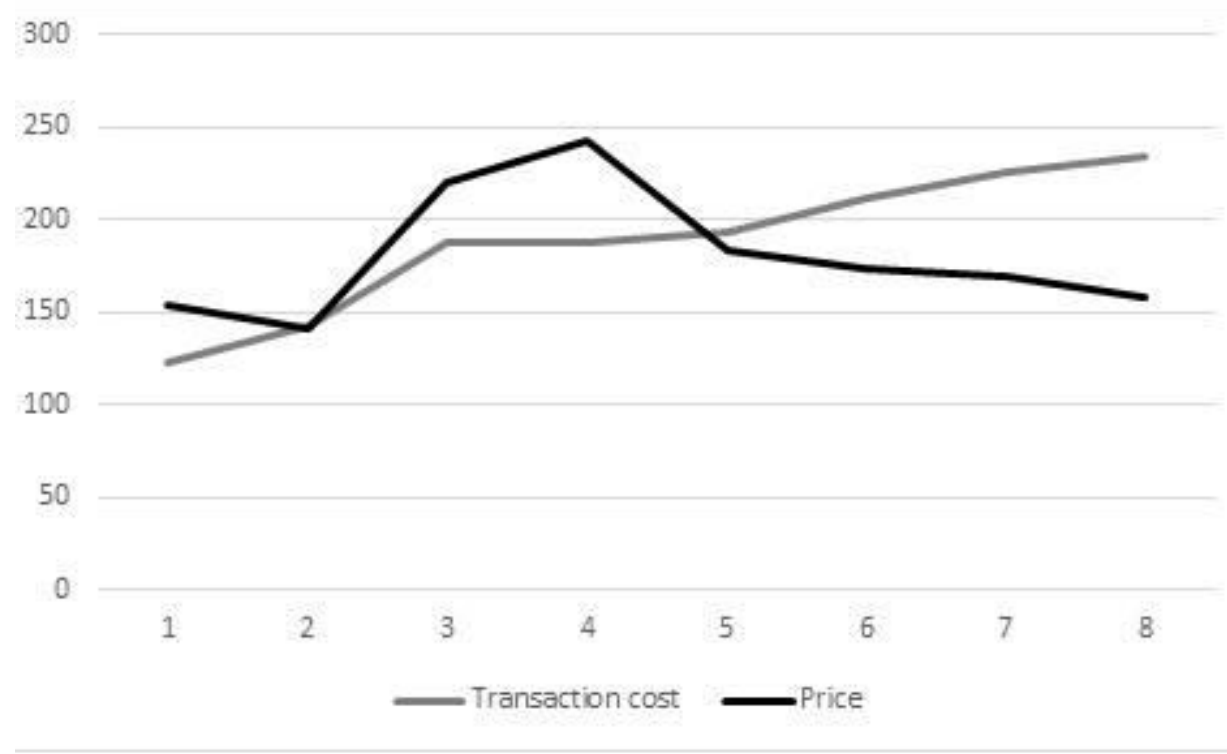

Prices for period/euro Transaction cost period/euro

Figure 3. Comparison between the variation of average costs and average price in different periods

Figure 3 depicts a comparison of the impact of legislation - in several periods. By comparing the average costs of several deals to the average prices of real estate property, an evaluation can be performed. If the increase in prices is greater than the one in costs, then the institutional environment is improving. Vice versa, if the average transaction costs increase faster than price, the institutional environment gets worse. This correlation between the described two effects - average amount of transaction costs and average price of real estate property - can be used as a guideline for solutions for concrete change of rules. Sometimes, the changes in the relative prices of assets can also be used for evaluation of institutional adaptation. The method can help for the development of legislation oriented directly towards agricultural activities on a micro-level.

\section{CONCLUSIONS}

The current research integrates several methods into a complex approach for a new institutional analysis and possibilities for the evaluation of adaptation. Institutional change, contract mechanisms and their influence, and also the alternatives of their effects measured by means of transaction costs, can be a source of both short-term and long-term solutions. The agricultural sector in this study is used just as an example. Undoubtedly, the adjustment of the presented methodology can contribute to the improvement of each abstract economic structure on a practical level.

\section{REFERENCES}

1. Meyer-Gerbaulet, H., Batho, H. L., Grozdanova, D., The Dependence of the Effective Border Controls on Appropriate Resources Deployment and Enhanced 
International Cooperation. Conference of the OIE, pp. 29-60, 2010.

2. North, D., Institutions, Institutional Change and Economic Performance. Cambridge University Press, 1990.

3. Eggensson, T., Economic Behaviour and Institutions. Cambridge Surveys of Economic Literature, 1990.

4. Stiglitz, J., Incentives and Risk-Sharing in Sharecropping. Review of Economic Studies, 41, 219-255, 1974.

5. Williamson, O., Markets and Hierarchies, Analysis and Antitrust Implications: A Study in the Economics of Internal Organization, 1975.

6. Cheung, S., Private Property Rights and Sharecropping. Journal of Political Economy. 76 (6): 107122. doi:10.1086/259477, 1968.

7. Coase, R., The Problem of Social Cost. Journal of Law and Economics. 3 (1): 144. doi:10.1086/466560, 1960.

8. Demsetz, H., Toward a Theory of Property Rights. Classic Papers in Natural Resource
Economics, pp. 163-177, DOI 10.1057/9780230523210_9, 2000.

9. Buchanan, J., The Collected Works of Volume 6 ,Cost and Choice: An Inquiry in Economic Theory“, published by University Of Chicago Press, p. 85, 1979.

10. Mises, L., Human Action: A Treatise on Economics, Scholar Edition, 1949.

11. Benham, Al., L. Benham, Br. Gunia, M. Jaramillo, M. Shirley, and D. Zylbersztajn, Questionnaire on Costs of Exchange: Registering a New Firm Officially. Ronald Coase Institute, Working Papers, Number 3, pp. 1-26, 2004.

12. Allen, D. and D. Lueck, Contract Choice in Modern Agriculture: Cash Rent Versus Cropshare. The Journal of Law and Economics, 35(2):397-426, DOI: 10.1086/467260, 1992.

13. Hubbard, M., The 'New Institutional Economics' in Agricultural Development: Insights and Challenges, Journal of Agricultural Economics, 48 (2), 239-249, 1997. 